\title{
Changing identities, changing realities: Social work research in a cold climate
}

\begin{abstract}
Andrew Whittaker ${ }^{1}$
Abstract: The potential of a researcher development initiative (RDI) programme to develop capacity within the social work discipline will be explored from my personal perspective as a former participant in one of the earlier RDI programmes. Having undertaken the programme after entering an academic post from practice, I hope to illustrate some of the challenges that new academics face and how such programmes can provide support in the transition from practitioner to academic, both as a lecturer/ teacher and a researcher. The strengths and limitations of such programmes will be explored, including measures to address systemic weakness in social science research in the UK. I will argue that, although such programmes cannot change the everyday realities of insufficient time and dwindling research funding, they can provide a genuinely welcoming and supportive introduction to the world of social work research that helps new academics and early career researchers to negotiate these realities with increased knowledge, skills and confidence.
\end{abstract}

Keywords capacity building; research culture; careers; methodological pluralism; quantitative research; transition

1. Senior Lecturer in Social Work, London South Bank University, and Honorary Research Fellow, Tavistock Clinic

Address for correspondence: Faculty of Health and Social Care, London South Bank University, 103 Borough Road, London SE1 OAA, England.whittaka@lsbu.ac.uk.

Date of publication (online): 20th Octcober 2012 


\section{Introduction}

I began working as a senior lecturer in social work at London South Bank University six years ago, after working in a child protection team, a child and adolescent mental health clinic and an adult mental health voluntary organisation. After spending eighteen years working in the field, it was a challenge to develop a new identity as an academic, both as a lecturer and researcher. Few social work academics follow the traditional career path of a first lecturing post after a doctorate in their twenties and it is more likely that they enter in their forties and fifties after a career in practice, like myself. I started the RDI when I was less than two years into the post, when I felt that I had started to get to grips with the teaching role and was completing a teaching course. The research part of my role felt like new territory so when the RDI was announced, it seemed timely.

\section{Establishing an identity as a researcher}

A crucial part of the experience was starting to establish an identity as a researcher (Brydon and Fleming, 2011). Like many participants, I found that teaching responsibilities are more immediate and more familiar. Teaching was a dance in which I had experienced one role as a student and was now learning to take the lead. But research was either dancing alone (where you have more freedom but still worry that you're 'doing it right') or dancing in a group where everybody else seemed to know the moves whilst I was still looking at my feet.

One of the most common challenges was protecting the time for research. Like most new staff, I was teaching modules for the first time, completing a teaching qualification and taking on administrative roles. Talking with colleagues from across the county, I became aware that many were in less supportive environments than my own. It was fascinating to hear how they managed to balance the different roles and protect precious time for their research in the face of the sometimes overwhelming demands of teaching and programme management (Lewis, 2003).

Alongside the RDI programme, I started to teach the research methods module to final year undergraduate students and postgraduate students. Whilst postgraduate students often had some previous knowledge and experience of research, it was usually new for undergraduate students. However, for both groups the idea of 'research' came with significant cultural baggage in the form of highly stylised perceptions of what research is. One perception was that 'research is boring', a view that I sympathised with when I was a practitioner and harassed user of research. On the occasions when I was able to attend a conference, I was interested to hear findings but when audience members started asking about methodology, I would inwardly groan and roll my eyes because the 'under the bonnet' workings were of little interest to me. 
A second and more problematic perception by the students was that research must be 'scientific', with the researcher removed from the picture and capable of complete 'objectivity', in a way that at times appeared to be a caricature of naive positivism. Intrigued by this, a colleague and I undertook several focus groups to understand student perceptions of research. What we found was that students perceived other professional groups, such as psychologists and medical doctors, as active researchers but they did not perceive their own discipline as creators of research. Yet when they were asked to identify a study that had influenced them, all but one of these studies was carried out by social work researchers (Whittaker and Goodyer, 2009).

Another worrying, though not surprising, finding was the only a third of postgraduate students felt confident about understanding quantitative research compared to almost three-quarters who felt confident about qualitative research (Whittaker and Goodyer, 2009). Even students with first degrees that required a high level of numerical competency described feeling unsure. However, this does not appear to be an issue that is confined to social work, as a study of $\mathrm{PhD}$ students across the social sciences found $78 \%$ chose qualitative approaches (Wiles, et al., 2009). It is encouraging to see a new RDI initiative to address this systemic weakness in social work research, which supports the teaching of quantitative research at undergraduate level by creating a shared common curriculum. In the short term, this should increase the literacy of social work students in quantitative research and increase the likelihood of doctoral studies using quantitative methodologies in the long term.

When I started teaching the undergraduate research module, I struggled to find texts that students found accessible. Although there have been some excellent texts produced recently, at that point many texts assumed that students already had an understanding of research terminology and the confidence to persevere when things got complicated. I developed the cynical view that a few texts seemed to have been written to impress academic colleagues rather than help students.

The RDI gave me the confidence to approach a student-friendly publisher, Learning Matters, who commissioned me to write an introductory textbook (Whittaker, 2012). A colleague told me that she had written a book by writing on Sunday afternoons and evenings for a year, which seemed to be a realistic commitment. In reality, I discovered that my writing is far slower and so the book became a substantial commitment over eighteen months, but an enjoyable project.

\section{Working in a research centre}

After the RDI, I secured a two-year secondment as projects coordinator and research fellow at the Centre for Social Work Research at the Tavistock Clinic and UEL, where I continue to be involved as an honorary research fellow. At the interview, I specifically discussed the knowledge and skills that I learnt through the RDI programme and 
found that I was able to use much of what I had learnt in my everyday work. The Centre for Social Work Research is led by Professor Stephen Briggs and has developed a 'practice near' research that emphasises the need for a close relationship between practice and research and more inclusive approaches to knowledge generation that address practitioner concerns and are close to their lived experience.

It has been an exciting time because I have been totally immersed into the world of research. Having been prepared for bid writing by the RDI, the realities of short deadlines and detailed methodologies was demanding but highly enjoyable. Whilst the world annual rhythms of teaching are highly predictable, the deadlines create 'work spikes' that are a challenge to manage. Working within a research team has been highly enjoyable and brings a closeness from working intensely on projects. It has been a fascinating experience in a rich and stimulating environment and enabled me to be involved in a range of projects, from an evaluation of healthcare needs within prisons (McCaffrey, et al, 2010) to a study of child abuse linked to beliefs in witchcraft and spirit possession (Briggs, et al, 2011).

What has struck me through these experiences is how intense and competitive the research world is. Not competitive at a personal level because I have had some rewarding collaborations, but competitive at a macro level, particularly given the financial context. A range of public bodies who formerly funded research have been abolished or substantially reformed. This presents substantial challenges to research centres who must compete harder for part of a dwindling pool of resources.

\section{Research and teaching: Competing identities?}

During the transition from practitioner to academic, I came to learn that the role of an academic is at least two roles, most commonly expressed as 'teaching' and 'research'. I had many discussions with fellow participants on the programme and learn that most regarded themselves as having a primary allegiance to one or other of these roles. Some participants strongly identified themselves as researchers and experienced teaching as time away from their core work. Others identified themselves as teachers and regarded research as an imposed burden that they had to engage with to be regarded as 'serious' academics. When I came into academia, I fell into the second camp and was sceptical about lecturers being expected to be 'research active', regarding it as pandering to an idea of 'research' as a high status activity. The idea that lecturers should still retain active practice roles seemed to be more useful, but not sufficiently high status to be encouraged.

Shortly after starting the RDI, I enrolled for a PhD that explores professional judgement in child protection. My study was rooted in my own practice experience, which is quite common in social work doctorates (Brydon and Fleming, 2011).

What has surprised me is that my experiences of research have deepened my 
identity as a teacher. My doctoral study has involved me spending extensive periods of time shadowing social workers in their everyday activities and interviewing them and managers about what makes them good at what they do. It has involved reading a significant body of literature related to this and evaluating the competing messages that they provide. Having the opportunity of observing and thinking rather than doing has been a considerable privilege and has enable me to think about practice in a much deeper way than when I was actually in practice. When I am in the classroom, I feel more passionately about what I teach and can provide examples from the literature and my data to illustrate what I am saying. Above all, engaging in research has led to me feeling 'in love' with my subject again, which is both enjoyable and necessary to sustain the daunting amount of work involved. I am reliably informed that this honeymoon feeling rarely lasts throughout a doctorate and can reverse into the most intensive dislike and even hatred in the final stages so I may feel quite differently in six months time.

\section{Discussion}

Like any programme, the RDI has strengths and limitations. One of the strengths of the programme was the methodological pluralism and diversity that was represented on the programme. I particularly remember writing a book chapter on research designs and preparing to draft a section on randomised controlled trials, expecting to end with the standard social work platitude that they are rarely used in social work. Fortunately, there was a two-day workshop on experimental and quasi-experimental designs that presented a convincing argument that RCTS have significant potential for social work research, based upon a number of successful RCTs already completed. I subsequently wrote that section with a much greater knowledge and confidence as well as an increased scepticism about the usual platitudes that are promoted about social work research.

An important part of the programme was challenging some of the myths around research and research funding. For example, it was easy to believe that research funding was only received by a few older and more prestigious universities. Consequently, it was encouraging to hear about the range of new universities that had been remarkably successful in securing research funding. Another strength was the atmosphere of openness and sharing, created by the candour and generosity of the key figures. Sometimes self-deprecating, often candid about the realities of seeking funding and completing projects, they always gave generously of themselves. This was so important in creating a sense of community in a field where researchers and research centres are often in direct competition with one another for increasingly scarce resources. It would have been far easier for senior researchers to hang onto hard-won knowledge, but they conveyed a commitment in investing in 
the next generation of social work researchers. As the REF approaches, the pressure increases for researchers to focus on institutional interests in a competitive system, which presents challenges to the spirit of collaboration that was central to the RDI initiative.

Such programmes cannot, of course, change the everyday realities of social work academics, who must juggle teaching, research and administrative responsibilities and priorities. Nor can they change the funding realities, where research centres are chasing dwindling research funding in an increasingly adverse financial climate. One of the issues that the RDI programme raises is how effectiveness is measured. Participation in the RDI was designed to encourage an increase in ESRC applications from the social work discipline. Since I did not submit an ESRC application, my involvement with the RDI could be seen as a 'failure'. Hopefully, I have conveyed a sense of what I personally gained that is wider than such limited 'performance indicators' and of how the programme contributes towards building the capacity, potential and infrastructure of social work research.

\section{Summary}

As I look back at the RDI programme, it represents an intensely collegiate introduction to the world of research. I gained a far fuller knowledge of the practical realities of particular methodologies than can be learnt from textbooks and the confidence to start to engage in the competitive world of research funding. Above all, I gained a sense of identity, both as an individual researcher and as a part of a wider social work research community.

The programme provided a genuinely welcoming and supportive introduction to the world of social work research that helped me to build an identity and confidence as well as skills and knowledge. Whilst such programmes cannot change the everyday realities of insufficient time and other resources, they can enable new academics and early career researchers to understand and negotiate these realities and cope with them with increased knowledge, skills and confidence.

\section{References}

Briggs, S., Whittaker, A., Linford, H., Bryan, A., Ryan, E., and Ludick, D. (2011) Safeguarding Children's Rights: Exploring issues of witchcraft and spirit possession in London's African communities. London: Trust for London. Available at: www.trustforlondon.org.uk

Brydon, Kand Fleming, J (2011): The journey around my PhD: Pitfalls, insights and diamonds, Social Work Education, 30, 8, 995-1011 
Lewis, C. (2003) Preparing the next generation of researchers. Social Work Education, 22, 6, $577-587$

McCaffrey, T., Briggs, S., Linford, H., and Whittaker, A. (2010) South East Coast Offender Health Project Board: Final Report. London: The Centre for Social Work Research, Tavistock and Portman NHS Trust and University of East London http://www.uel-cswr.org/resources/documents/SECOffenderHealthFinalReport040810.pdf Whittaker, A. (2012) Research Skills for Social Work. London: Learning Matters.

Whittaker, A. and Goodyer, A. (2009) Pedagogy of the Perplexed; Moving research methods teaching beyond 'white men in white coats'. Conference paper, JSWEC, University of Hertfordshire

Wiles, R, Durrant, G, De Broe, S and Powell. J. (2009) Methodological approaches at PhD and skills sought for research posts in academia: A mismatch? International Journal of Social Research Methodology, 12, 3, 257-269. 